\title{
A Novel Transportation Method Based on Dynamic Control of Ripening Environment
}

\author{
Xinyu Liu, ${ }^{1, *}$ and Xiaojie Jin ${ }^{2}$ \\ ${ }^{1}$ Department of Vehicle Engineering, Yantai Automobile Engineering Professional College, Yantai 265599, China \\ ${ }^{2}$ College of Control Science and Engineering, Zhejiang University, Hangzhou 310027, China
}

Received 3 June 2020; Accepted 28 August 2020

\begin{abstract}
The dynamic control of atmosphere is an important factor for guaranteeing the quality of climacteric products during transportation. As atmosphere changes, respiration climacteric products would rot because of overripeness, thus leading to loss. Moreover, climacteric products must be ripened artificially when delivered to the destination, thereby causing economic waste. In this study, a new transportation method based on dynamic control of ripening environment was designed.The ripeness control method based on the dynamic control of ripening atmosphere was presented to accomplish quality safety during transportation as well as avoid a subsequent extra process of ripening. The transportation method was employed to stem from the ethylene's ripening effect on climacteric fruits and vegetables. The ethylene generator and air circulation unit, which dynamically regulate and control the dual regional atmosphere of carriages during transportation, were quantitatively controlled by the central treatment layer. Ripeness level could be regulated by controlling the temperatures and time of exogenous ethylene release, to control the quality of products and ripen them. The proposed method was proven feasible through experiments. Results demonstrate that a volume fraction of $0.01 \%$ exogenous ethylene allows bananas' respiratory intensity to reach the peak early; meanwhile, moderate low temperature $\left(16^{\circ} \mathrm{C}\right)$ can enable ethylene peak to appear in advance. Therefore, bananas' ripeness can be controlled by changing temperatures and the ripening environment when transporting. This study can provide references for the control of products' ripeness during transportation.
\end{abstract}

Keywords: gas ripening, ethylene concentration, controlled atmosphere method, dynamic control

\section{Introduction}

The value of fruits and vegetables lies in their freshness. Transporting radius and trading time are limited on account of seasonal, regional, and perishable features. The loss during transportation can be caused by overripe and rotten fruits. Respiration climacteric products, whose quality and physio-biochemistry indexes change significantly before and after climacteric, suffer short-period freshness and perishableness. Approximately $20 \%-30 \%$ unprocessed fruits and vegetables during transportation are overripe and rotten every year due to the lack of equipment and professional techniques: the number of rotten fruits and vegetables is nearly 12 and 130 million tons, respectively, in China, both of which cause approximately 80 billion in economic losses every year [1-2]. The reasons for losses during transportation are as follows: (1) Improper concentration control of ripening gas - ethylene is the main and crucial component in ripening gas. A high concentration of ethylene can promote fruit ripening and sugar hydrolysis for accelerating the perishableness of fruit, thereby complicating transportation [3-8]. (2) Unreasonable loading methods -piling up the goods in traditional carriages leads to the squeezing of goods at the lower level; meanwhile, the goods at the higher level wobble and collide due to the lack of fixation, thus damaging fruits and vegetables and accelerating their perishableness [9]. Therefore, a new type of transportation method must be developed.

\footnotetext{
*E-mail address: xyliu77@126.com

ISSN: $1791-2377$ @ 2020 School of Science, IHU. All rights reserved.

doi:10.25103/iestr.135.08
}

Currently, scholars from China focus mainly on studying the temperature control of climacteric products but less on specific model results on ethylene control [10-13]. Various problems, such as the inaccuracy of key-parameter control (temperature and ethylene concentration) and low automation level, exist although controlling ethylene in the transportation method has been studied in Europe and other countries. At present, there are less research findings on transportation methods where ethylene concentration can be regulated and loading modes can be changed as well.

For the above reasons, a novel transportation method with multi-functional controlled atmosphere is designed in this study on the basis of ethylene's effects of ripening on respiration climacteric fruits and vegetables, thereby building control models of ripening gas intensity. The method is based on the relationship between the change in temperature and exogenous ethylene and fruit-vegetable ripeness. Ripeness level can be regulated by controlling the temperatures and time of exogenous ethylene release, to control the quality of products and ripen them. The feasibility is verified that ripeness level can be controlled by regulating carriage temperatures and the time of exogenous ethylene release. This method can provide a certain reference for controlling the ripeness level of products during transportation.

\section{State of the Art}

In recent years, scholars worldwide have studied storagetransportation, examined the ripening links of respiration 
climacteric products, and analyzed the influence of storagetransportation and ripeness conditions on quality. The effect of storage temperature and humidity and atmosphere components $\left(\mathrm{O}_{2}\right.$ and $\left.\mathrm{CO}_{2}\right)$ on respiration climacteric fruits, such as plums, had been investigated (BRAT, P et al., 2020) [14-15]. Wang et al. (2016) concluded through experiments that fresh bananas in sales should be ripe at a low temperature $\left(16 \pm 0.5^{\circ} \mathrm{C}\right)$ by controlled atmosphere, whereas the appropriate temperature for mass ripening bananas is $19 \pm 0.5^{\circ} \mathrm{C}$. Properly lowering the temperature could reduce bananas' quality in the later phase of ripening [16]. He et al. (2017) indicated that high energy level could be maintained at an appropriately low temperature $\left(14^{\circ} \mathrm{C}\right)$ to delay fruit overripening, by studying temperatures' influence on bananas' energy after being picked to analyze the ripening status. However, in terms of different ripeness levels, the appropriate ripening temperature for bananas was not analyzed [17]. Kargar et al. (2019) used bananas with different plumpness as study subjects and discussed how storage time, ripening temperature, and ripening time affected the ripening speed. Nevertheless, the internal mechanism that bananas with different ripeness levels had susceptibility differences of ethylene in the early stage of banana picking was ignored [18]. Rayo-Mendez et al. (2019) designed the ethylene ripening method of fruit-vegetable and acquired various parameters, such as temperature, humidity, ethylene, and $\mathrm{CO}_{2}$, all of which could automatically control the accuracy of ripening required after fruit-vegetable picking. Nevertheless, optimal ripening parameters that are required for different kinds of fruitvegetable and different varieties of the same fruit-vegetable are yet to be determined in practical cases [19]. Shang et al. (2014) utilized Williams bananas with $70 \%$ ripeness as testing materials and treated the bananas with $40 \%$ ethephon solution at different temperatures and concentration. The finding indicated that using $1000 \mathrm{mg} / \mathrm{kg}$ ethephon solution at a normal temperature $\left(22^{\circ} \mathrm{C}\right)$ was optimal in terms of banana ripening; however, food safety problems caused by ethephon had not been addressed [20]. Borges et al. (2019) proposed that vibration could stimulate the physiological response and quality change of kiwi fruit. Weight loss rate, solubility, solid content, cell membrane permeability, respiratory intensity, and ethylene release amount are significantly increasing. The greater the vibration intensity was, the greater the effect on kiwi fruit physiology and quality was. However, measures for reducing vibration loss during transportation were not involved [21]. Through experiments, ethylene treatment had a marked effect on content of phytochemicals in red grapefruit during transportation (Priyanka R. Chaudhary et al.,2015) [22]. Lim et al. (2017) showed that exogenous ethylene's commercial use in the normalized ripening of 'Jecy green' kiwi fruit could bring good quality to the fruit without a side effect [23]. Hertog et al. (2016) established the softening model of kiwi fruit, which reflected the response to time, temperature, and exogenous ethylene level during transportation [24]. Mata et al. (2019) indicated that ethylene production level dropped sharply at a low temperature and a storage temperature of $10^{\circ} \mathrm{C}$, compared with $18^{\circ} \mathrm{C}$, considerably inhibited tomato ripening, thus changing the regulation of ethylene biosynthesis pathways [25]. Saraiva et al. (2018) determined the optimal ethylene treatment dosage during ripening, in combination with fruit ripening parameters, based on the physical, biochemical, and physiological characteristics of Thap Maeo fruit [26]. Gwanpua et al. (2018) established a mathematical model that described autocatalytic ethylene production, which is coupled with the one that described ethylene softening and color change; the model was used to assist in predicting the effects of temperatures, exogenous ethylene, and time on Hass avocado's quality [27]. Saraiva et al. (2018) studied and confirmed the ethylene amount by using the optimal parameters for handling ripening fruits [28]. Amoah et al. (2017) examined a lab-scale device that regulated a variable gas concentration and flow rate, which could supply exogenous ethylene for fruit-vegetable storage [29].

The abovementioned transportation methods mainly focused on respiration climacteric products that were affected largely by the transportation environment, including the influence of storage-transportation, atmosphere temperatures, and ethylene concentration on the ripening process, and that fruit shelf life could be predicted by testing various indexes, such as firmness, skin color, and soluble solids. However, few scholars were involved in ripeness level, particularly the study of controlling ripeness level by changing the outside environment during transportation. Consequently, the present study developed a control method by considering that ripeness level can be controlled by temperature and ripening gas. Moreover, the model of ripening gas concentration was established, thereby designing a multi-functional controlled atmosphere method, based on the relationship between the change in temperature and exogenous ethylene and fruit-vegetable ripeness. Practical experiments and analysis verified that the ripeness level can be controlled by regulating carriage temperatures and exogenous ethylene release time, which provides clues to ripening and ripening control during transportation.

The remainder of this study is organized as follows: Section 3 describes what constitutes the multi-functional controlled atmosphere method and how it operates, constructs calculation models controlled by ripening gas concentration, and introduces the basic process of banana ripening experiments and its related indexes. Section 4 indicates that changing temperatures and exogenous ethylene can control the ripeness level of fruits and vegetables through experiments and the analysis of color, firmness, starch, respiration intensity, ethylene release amount, and soluble solids during actual transportation. Section 5 summarizes the conclusions.

\section{Methodology}

\subsection{Physical Model}

\subsubsection{Method Composition and Working Principle}

Various specifications are used in different transportation situations in China, as carriage specifications of a large vehicle during fruit-vegetable transportation vary greatly [30]. Generally, the carriage used for refrigerated transportation has a dimension of $9.6 \mathrm{~m} \times 2.3 \mathrm{~m} \times 2.7 \mathrm{~m}$, based on which the method is optimized and transformed to construct a multi-functional controlled atmosphere, as shown in Figure 1. The transportation method consists of the central gas treatment layer, automatic loading and unloading, and air circulation. The central gas treatment layer divides the carriage into two zones of $A$ and $B$ to achieve the multimodal transport of products in different categories or products with different ripeness levels in the same category. Meanwhile, the function of its bidirectional controlled atmosphere can regulate the ethylene concentration, for example, when ethylene concentration in zone A is relatively 
low and zone B is relatively high, the central gas treatment layer can extract a part of ethylene in zone B and release it to zone A to utilize exogenous ethylene fully, which reduces squeezing and vibration loss by the special loading and unloading method, thus lowering loss.

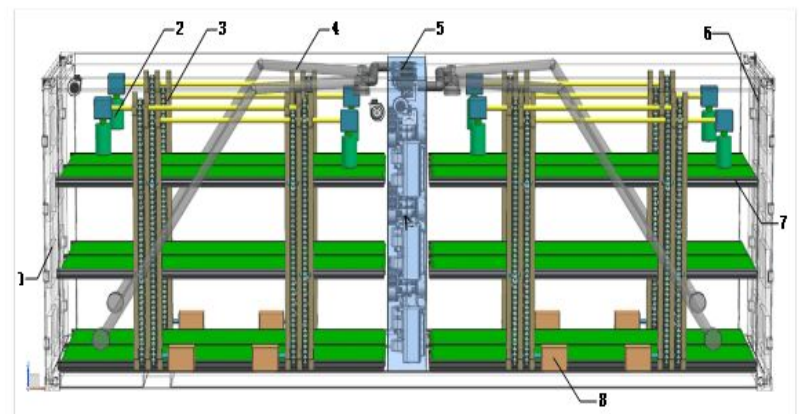

1. Front Double-door unit 2. Ethylene gas tank 3. Rise-fall sprocketchain 4. Air circulation tube 5. Central gas treatment layer 6. Rear Double-door unit 7. Lifting plate 8 . Gear motor

Fig. 1. Overall design of the CA transportation method

The working process of carriages is as follows: 1) Goods are delivered with conveyor belts from the lower lifting plate up to the carriage, and the conveyor belt stops operating when touching the central gas treatment layer. This process is repeated until goods are fully loaded, and then the conveying device stops working and the plate of this layer complete its loading. When the lifting device starts and the lifting plate rises until it reaches a position where no damage is caused by pressure to goods and that has a fixating role, the layer of lifting plate stops operating and locks up. The lower lifting plate delivers the goods in the same way, with cycle repeating until the carriage is fully loaded, and finally the delivery stops and the carriage is closed. 2) The bidirectional controlled atmosphere method and carriage refrigeration in central gas treatment layer are started. According to the requirements for the ripeness of zone A and B's goods, the carriage that needs ripening is regularly replenished with ethylene gas, or some ethylene extracted from the zone with high concentration is released to the zone with low concentration, through which zones A and B have proper ethylene concentration, as shown in Figure 2.

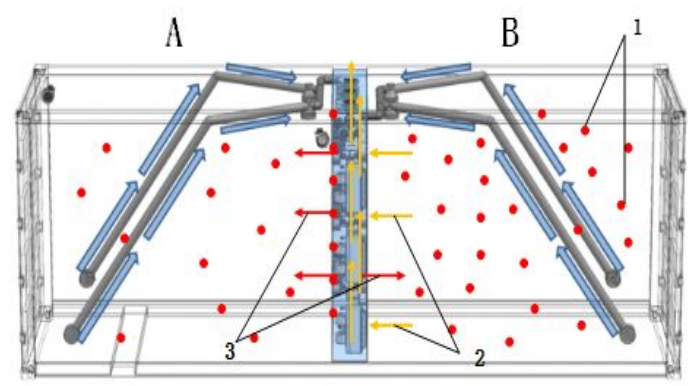

Fig. 2. Schematic of working principle

Red spot 1 is ethylene, and the process where ethylene with high concentration is extracted by the central gas treatment layer is marked by 2 . Process 3 is when concentration ethylene is low, and the central gas treatment layer releases ripening gas to increase concentration.

\subsection{Design and Analysis of Key Components}

\subsubsection{Central Gas Treatment Layer}

As shown below, the central gas treatment layer consists of refrigeration, ethylene-generating, and intake-and-exhaust units, thereby dividing the carriage into the front and back zones. The refrigeration unit inside the carriage can start cooling or shut down as required during operation. The ethylene-generating unit, which utilizes the mechanism that ethephon dissolves in water to produce ethylene, can pass ethylene produced through the tube to the intake-andexhaust unit. Simultaneously, the ethylene-generating unit chooses to generate ethylene for discharging or not based on the setting of ripeness level. During transportation, the central gas treatment layer can select the working state based on the different ethylene concentrations of the front and back zones and regulate the carriage's ethylene concentration by coordinating components by the method.

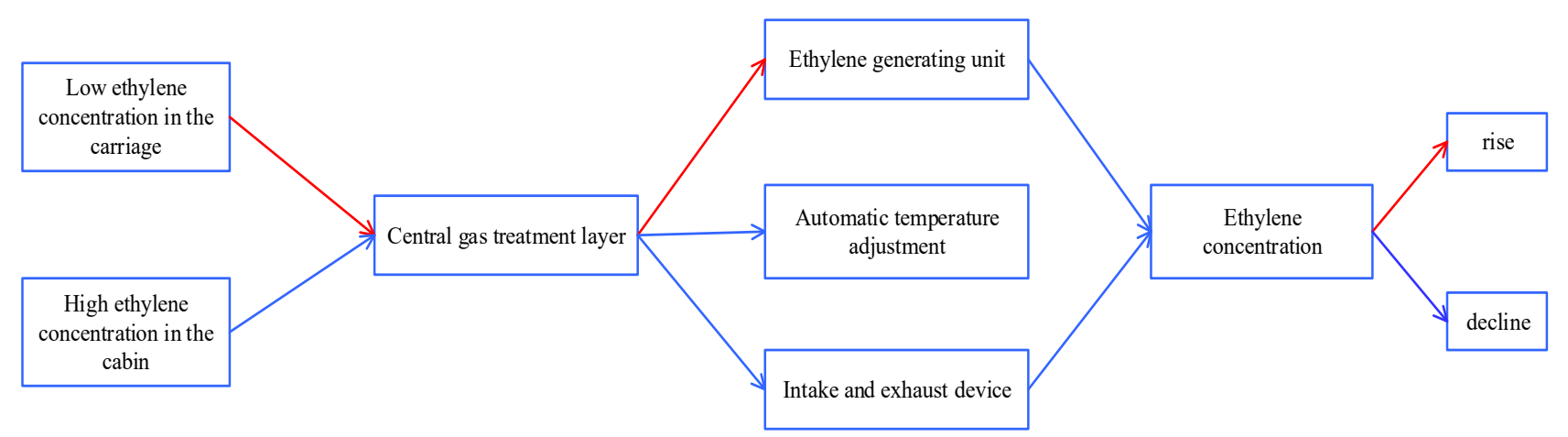

Fig. 3. Flow chart of ethylene regulation in the central gas treatment layer 

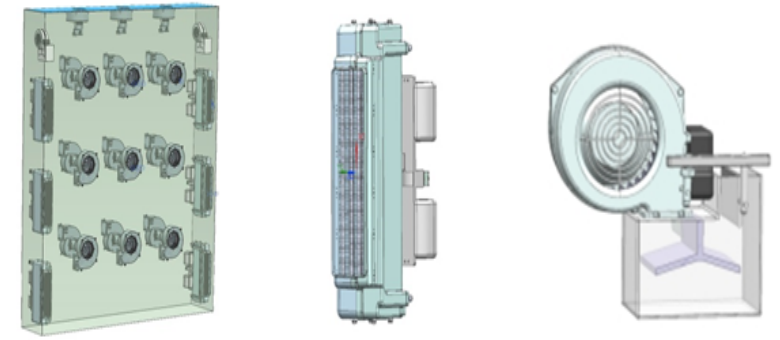

a. Central gas treatment layer

b. Refrigeration method

d. Ethylene generating unit

Fig. 4. Design of central gas treatment layer

The lateral wall of the central gas treatment layer is equipped with the refrigeration device, which is responsible for temperature environment adjustment. The upper side of the lateral wall consists of ethylene-generating units. Nine air extractor and exhaust units are evenly placed in the front interior, with another three on the top, which can carry out gas exchange in the device.

A refrigeration device, which is converted from a traditional compressor, is fit for installing in a small-size central gas treatment layer. Six refrigeration devices are coordinated, working together, thus enhancing the operating efficiency of the central gas treatment layer and achieving an improved cooling effect.

The ethylene-generating unit is designed by utilizing the property that ethephon dissolves in water and produces ethylene gas, as shown in Figure 4. The upper part is a small fan, and the underpart is a container with water wherein ethephon dissolves. The container is airtight when not in operation. When the ethylene-generating unit is operating, the fan is connected with the container, which drives the gas flow, thereby delivering ethylene to the tube connected to the air extractor and exhaust unit.

\subsubsection{Air Circulation Method}

Air circulation method is designed in the carriage interior to ensure internal and external pressure equalization and homogeneous gas composition (Figure 5). The ventilation duct of the air circulation method is set up on the inner wall of the carriage on both sides. When the device starts, the central gas treatment layer absorbs the gas from both sides, delivers it into heat transfer, and then discharges the gas to the inside of the carriage, thereby finally realizing the air circulation.

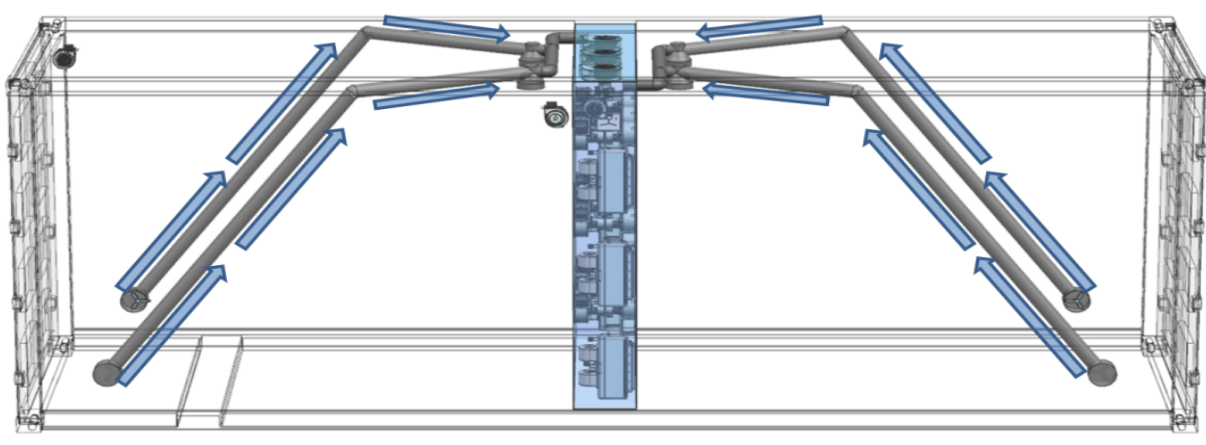

Fig. 5. Design of air circulation method

\subsection{Calculation Model}

The amount of ripening gas release is calculated as follows:

$$
W=\frac{C \times\left(\mathrm{V}_{1}-V_{2}\right)}{M \times H}
$$

Where $W$ is the amount of ripening gas release, $C$ represents the ripening gas concentration of the sample, $V_{1}$ denotes the carriage volume, $V_{2}$ signifies the sample volume, $M$ indicates the sample quality, and $H$ stands for the time of being airtight.

The minimum processing time that ripening requires is obtained as follows:

$Y=(0.04+0.02 K) T^{2}-(3+1.1 K) T+16 K-\left(22-1.3 T+0.02 T^{2}\right) \log _{10} X$

Ripening gas concentration is deduced from the time as follows:

$$
X=10 \frac{(0.04+0.02 K) T^{2}-(3+1.1 K) T+16 K-Y}{\left(22-1.3 T+0.02 T^{2}\right)}
$$

Where $Y=M T T, \quad X$ is exogenous ripening gas concentration, $T$ denotes the fruit temperature, and $K$ represents a real number.

\subsection{Experimental Model}

The experiment, with ripeness of bananas as the subject, is conducted through the actual transportation process. Control experiment parameters are configured by changing the temperature of the environment and the time of exogenous ethylene release dynamically. The carriage temperature is $16( \pm 0.5){ }^{\circ} \mathrm{C}$ without pre-treatment of the control group. The color, firmness, starch, respiratory intensity, ethylene-release amount, and soluble solids of bananas are analyzed in the experiment.

Information processing in this experiment can be divided into three phases, that is, data collection in the interior of the carriage, ethylene concentration regulation, and comparative analysis of banana ripening results. The comparative analysis includes measuring colorimetry, firmness, starch content, respiratory intensity, ethylene release rate, and soluble solids. Figure 6 shows the entire process. 


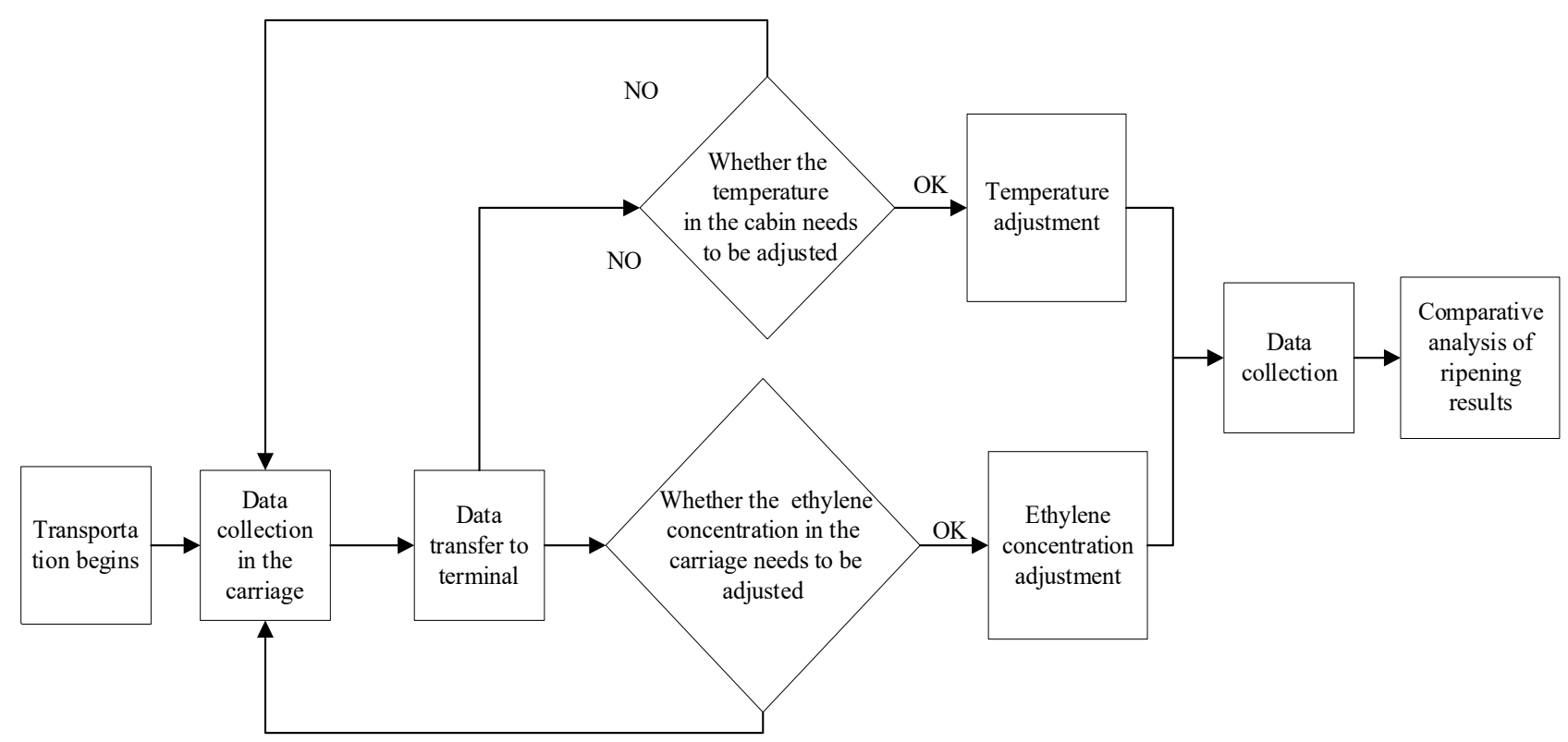

Fig. 6. Basic flow chart

\section{Experiment and Analysis}

\subsection{Materials and Equipment}

Bananas used in the experiment are obtained from a planting base in Zhanjiang City, Guangdong Province, China, and the variety is Williams. Bananas, when in $40 \%$ ripeness, are picked, and fruits with the same size and uniform colors are divided into small bunches; rotten fruit, diseased fruit, and fruit with damaged skins are excluded. Then, the bananas are rinsed with bleaching powder $(1.5 \mathrm{~g} / \mathrm{L})$, soaked in Sportak solution $(250 \mu \mathrm{l} / \mathrm{L})$ for $2 \mathrm{~min}$, and dried in air, as preparations for later experiment.

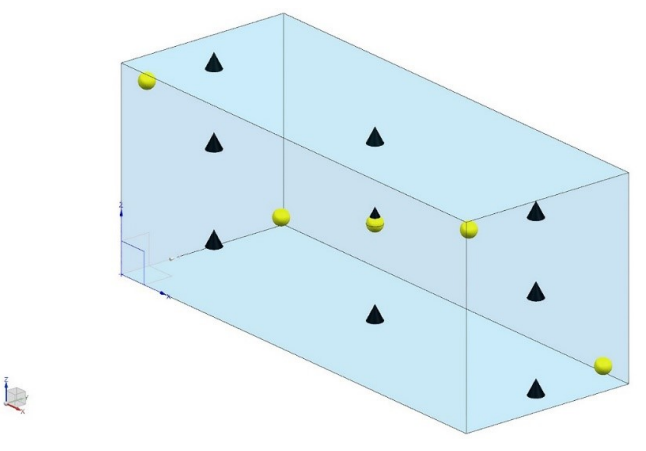

Fig. 7. Diagram of sensor stations

The vehicle used in the experiment is a refrigerated transportation vehicle with a dimension of $9.6 \mathrm{~m} \times 2.3 \mathrm{~m} \times 2.7 \mathrm{~m}$, equipped with controlled atmosphere method. Temperature and ethylene sensors are installed in the interior, and Fig. 7 shows their placement.
The instruments used in the experiment are ethylene gas cylinder, ethylene sensor, T2-X04 temperature sensor (Shenzhen Qianhai Yoului Technology Co., Ltd), NR-3000 automatic colorimeter, Shimadzu 2010 gas chromatograph, WZS-1 hand-held refract meter, and GY-1 Fruit Hardness Tester (Hangzhou Scientific Instrument Factory).

\subsection{Design of Experiment}

The transportation method is divided into three phases in this experiment. As shown in Table 1, Groups A, B, C, and D are listed for controlled tests to verify whether bananas during transportation can be ripened.

1) Group A, on the first day, is designated to release ethylene with a volume fraction of $0.01 \%$ to ripen bananas, with the temperature inside the carriage being kept at $16( \pm 0.5){ }^{\circ} \mathrm{C}$ during the entire transportation. Bananas with $70 \%$ of ripeness are expected when transported to the destination.

2) Group B, on the second day, is designated to release ethylene with a volume fraction of $0.01 \%$ to ripen bananas, with the temperature inside the carriage being kept at $16( \pm 0.5){ }^{\circ} \mathrm{C}$ during the entire transportation. Bananas with $60 \%$ of ripeness are expected when transported to the destination.

3) Group C, on the second day, is designated to release ethylene with a volume fraction of $0.01 \%$ to ripen bananas, with the temperature inside of the carriage being set at $16( \pm 0.5){ }^{\circ} \mathrm{C}$ for the first day but $25( \pm 0.5){ }^{\circ} \mathrm{C}$ for the second day. Bananas with $60 \%$ of ripeness are expected when transported to the destination.

4) Group D is the control group, with no pre-treatment and the temperature inside of the carriage being set at $16( \pm 0.5){ }^{\circ} \mathrm{C}$.

Table. 1. Control condition of controlled experiment in transportation process

\begin{tabular}{|c|c|c|c|c|c|c|c|}
\hline \multirow{2}{*}{ Group } & \multicolumn{7}{|c|}{ Transportation time } \\
\hline & $1 \mathrm{~d}$ & $2 \mathrm{~d}$ & $3 \mathrm{~d}$ & $4 \mathrm{~d}$ & $5 \mathrm{~d}$ & $6 \mathrm{~d}$ & $7 \mathrm{~d}$ \\
\hline $\begin{array}{l}A \\
B \\
C\end{array}$ & $\begin{array}{c}16{ }^{\circ} \mathrm{C} \text { ethylene } \\
16^{\circ} \mathrm{C} \\
16^{\circ} \mathrm{C}\end{array}$ & $\begin{array}{c}16^{\circ} \mathrm{C} \\
16^{\circ} \mathrm{C} \text { ethylene } \\
22^{\circ} \text { Cethylene }\end{array}$ & $\begin{array}{l}16^{\circ} \mathrm{C} \\
16^{\circ} \mathrm{C} \\
22^{\circ} \mathrm{C}\end{array}$ & $\begin{array}{l}16^{\circ} \mathrm{C} \\
16^{\circ} \mathrm{C} \\
22^{\circ} \mathrm{C}\end{array}$ & $\begin{array}{l}16^{\circ} \mathrm{C} \\
16^{\circ} \mathrm{C} \\
22^{\circ} \mathrm{C}\end{array}$ & $\begin{array}{l}16^{\circ} \mathrm{C} \\
16^{\circ} \mathrm{C} \\
22^{\circ} \mathrm{C}\end{array}$ & $\begin{array}{l}16^{\circ} \mathrm{C} \\
16^{\circ} \mathrm{C} \\
22^{\circ} \mathrm{C}\end{array}$ \\
\hline $\mathrm{D}$ & $16^{\circ} \mathrm{C}$ & $16^{\circ} \mathrm{C}$ & $16^{\circ} \mathrm{C}$ & $16^{\circ} \mathrm{C}$ & $16^{\circ} \mathrm{C}$ & $16^{\circ} \mathrm{C}$ & $16^{\circ} \mathrm{C}$ \\
\hline
\end{tabular}


The volume fraction of ethylene is $0.01 \%$; the allowable temperature fluctuation range is 0.5 ; the experiment ends on the seventh day.

The transportation vehicle set off at 9:00 a.m. on Oct. 23, 2019, in Guangdong Province. Ethylene concentration and temperature in the carriage were regulated based on the experimental values after the bananas were loaded; meanwhile, data were collected and transmitted by sensors. The key indicators, such as color, firmness, starch, respiratory intensity, ethylene release rate, and soluble solids were regularly measured during transportation.

The experimental vehicle arrived in Yantai (China) on Oct. 29, 2019, thus taking 6 days and $3 \mathrm{~h}$. Data from all indexes of the bananas were collected, recorded, and analyzed after the experiment. The data collected by temperature and ethylene sensors were exported, sorted out, and analyzed to verify whether bananas' ripeness was the same as expected.

\subsubsection{Determination of Chroma}

Pericarp chroma determination is conducted by referencing the method of Duan Xuewu. NR-3000 automatic colorimeter is used to measure the fruit color [31]. The working condition is that the spot diameter is determined to be $10 \mathrm{~mm}$ under $\mathrm{C} / 2$ light source, and $\mathrm{L}$ (glossiness) and $\mathrm{H}$ (chroma) values are measured and calculated using standard white board as a sample. The process is repeated 15 times.

\subsubsection{Determination of Hardness}

Each one in 10 bananas from the same batch is cut into three parts based on Su Xinguo's method. GY-1 Fruit Hardness Tester (Hangzhou Scientific Instrument Factory), whose pressure head with $4 \mathrm{~mm}$ diameter is cylindrical, is used to determine pulp firmness [32]. Three points in each banana are measured, with hardness unit being $\mathrm{kg} / \mathrm{cm}^{2}$.

\subsubsection{Determination of Starch Content}

The acid hydrolysis method [33] indicates that fat and soluble sugar in the sample should be removed first when measuring starch contents, and then starch is hydrolyzed to reductive glucose at certain acidity. The starch content is determined by multiplying the reductive sugar content with the conversion factor of 0.9 .

The calculation formula is as follows:

$$
W(\%)=\frac{m_{1} \times V}{m_{2} \times 1000} \times a \times 0.9 \times 100
$$

where $W$ is the starch content (\%), $m_{1}$ represents the standard sugar content of sucrose per $\mathrm{ml}(\mathrm{g}), m_{2}$ stands for the sample quality $(\mathrm{g}), V$ signifies the titration dosage $(\mathrm{ml})$, and $a$ denotes the dilution multiple.

\subsubsection{Determination of Respiratory Intensity and Ethylene Release Rate \\ By referring to Su Xinguo's method [32], 10 bananas are selected randomly from the experimental group and put in an airtight glass bottle $(6000 \mathrm{ml})$. After being airtight for $3 \mathrm{~h}$, $1 \mathrm{ml}$ gas is obtained and Shimadzu 2010 gas chromatograph is used to measure $\mathrm{CO}_{2}$ and ethylene concentration. The gas chromatograph works under the following conditions: usage of a flame ionization detector, column temperature at $90^{\circ} \mathrm{C}$, sample injector at $200{ }^{\circ} \mathrm{C}$, carrier gas of $\mathrm{N}_{2}$, flow rate at 10 $\mathrm{ml} / \mathrm{min}$. The process is repeated three times. Respiratory}

intensity and ethylene release rate are calculated based on the peak area, which references standard samples.

\subsubsection{Determination of Soluble Solids}

Based on Lian Shaobin's method [34], $10.00 \mathrm{~g}$ of banana pulp is weighed and ground in a mortar, a glass rod is dipped into a small amount of juice, and then a hand-held refractometer is used to measure contents of soluble solids.

\subsection{Result Analysis and Discussion}

\subsubsection{Changes of Banana Color}

$\mathrm{L}$ and $\mathrm{H}$ values can directly reflect the change in peel color. The higher the $\mathrm{L}$ value is, the glossier the peel is. When the $\mathrm{H}$ value drops, the peel turns from green to yellow. When it drops below 90, the entire peel completely grows yellow.

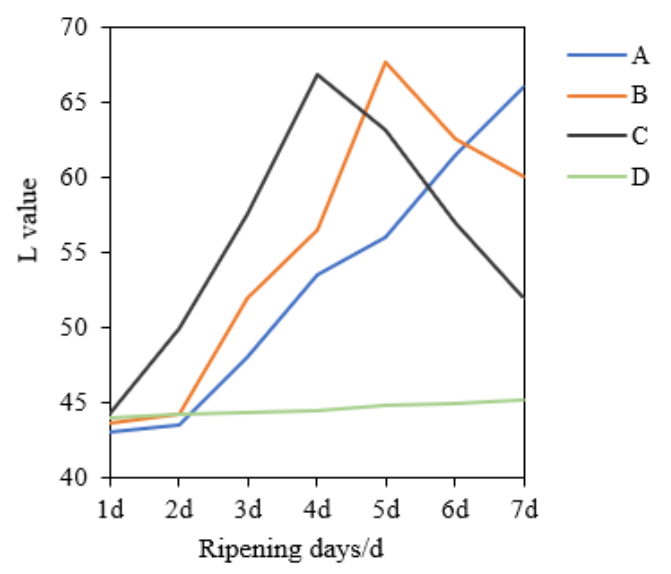

Fig. 8. Changes of banana peel L value

Figure 8 shows that the L value in Group D, among four groups of bananas, had no significant change during transportation, and in the remaining groups, the $\mathrm{L}$ values increased. The $\mathrm{L}$ value of Group A showed an upward trend, whereas those of Groups B and C initially increased and then decreased. After the first-day transportation, the $L$ value of Group A had a remarkable difference, compared with those of Groups B, C, and D, thereby demonstrating that bananas in Group A had begun ripening by the effect of ethylene. After the third-day transportation, the $\mathrm{L}$ value between Groups B and C differed greatly. During lowtemperature storage and transportation, the $\mathrm{L}$ values of Groups A and B sharply dropped and were lower than that of Group C, which indicated that ripening temperature had a relatively considerable influence on peel glossiness.

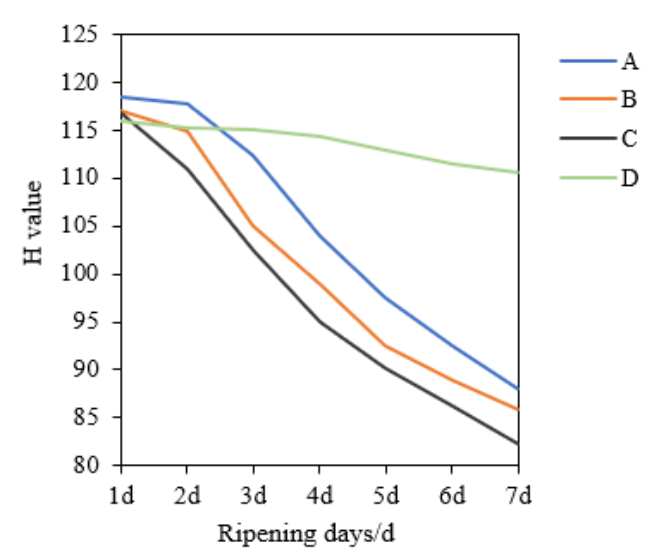

Fig. 9. Changes of banana peel $\mathrm{H}$ value 
Figure 9 presents that the $H$ values of bananas in Groups $\mathrm{A}$ and $\mathrm{B}$ rapidly drops after ethylene treatment, and on the sixth day, the values reached 92.54 and 88.97 , respectively, with the peel turning yellow. The $\mathrm{H}$ value of Group $\mathrm{C}$ decreased rapidly on the third day and the descending rate was higher than those of Groups A and B. Until the sixth day, the $\mathrm{H}$ value dropped to 86.17 with some little yellow spots in the peel, thereby showing that a high-temperature environment had an accelerating effect on bananas' ability to turn green into yellow.

\subsubsection{Changes of Banana Firmness}

Pulp firmness is one of the important indexes for bananas' after-ripening. Pulp firmness drops rapidly during afterripening; therefore, determining banana firmness is an important method for measuring the ripeness level.

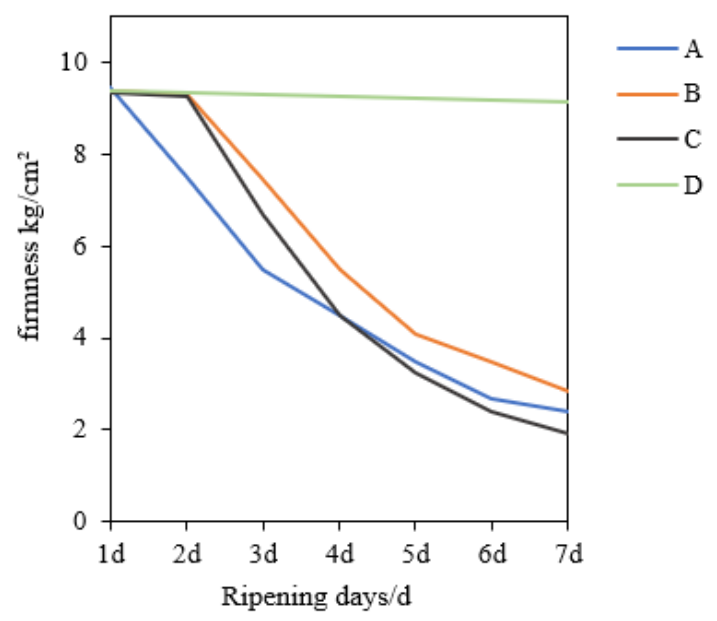

Fig. 10. Changes of fruit firmness during ripening of banana

Figure 10 shows that banana firmness in Groups A, B, and $\mathrm{C}$ decreased during transportation after exogenous ethylene application. The banana firmness in Group A, during second-day transportation where exogenous ethylene was working, dropped rapidly from 9.46 to 7.51 , thereby declining by $20.6 \%$. In Groups B and C, banana firmness, during third-day transportation, quickly decreased from 9.38 and 9.36 to 7.46 and 6.71 , thereby declining by $20.3 \%$ and $28.3 \%$, respectively. In Groups A, B, and C, the firmness dropped sharply in the early stage of transportation and changed slowly in the later stage. The firmness slightly changed in Group D. The data in Figure10 present that the change rate of banana firmness in Group $\mathrm{C}$ was higher than those in Groups A and B, thereby indicating that different ripening temperatures greatly affected the firmness and higher temperatures could expedite the decrease of fruit firmness.

\subsubsection{Changes of Starch Content}

The starch content in an unripe banana is $20 \%-25 \%$, whereas the content decreases and soluble polysaccharide accumulates in large quantities in the ripening process of a banana [35]. The data records suggest that bananas' starch content declines gradually in the process of being ripe due to the gradual transformation of starch into such soluble sugars as sucrose and glucose.

Figure 11 shows a downward trend in the starch content of Groups A, B, and C with ripening. Group A's starch content sharply declined on the second and third days and then tended to be stable. In Groups B and C, the decrease of bananas' starch content remained steady after dropping rapidly on the third and fourth days. Group C's starch content was always lower than that of Group B. Group D had no noticeable change in starch content. Figure 11 presents that the starch content of Group $\mathrm{C}$ decrease faster than those of Groups A and B, thereby indicating that the temperature had a great effect on the starch conversion rate in terms of the after-ripening of bananas. In a certain range, increased the environmental temperatures could further facilitate the after-ripening process of bananas, thereby accelerating the conversion of starch.

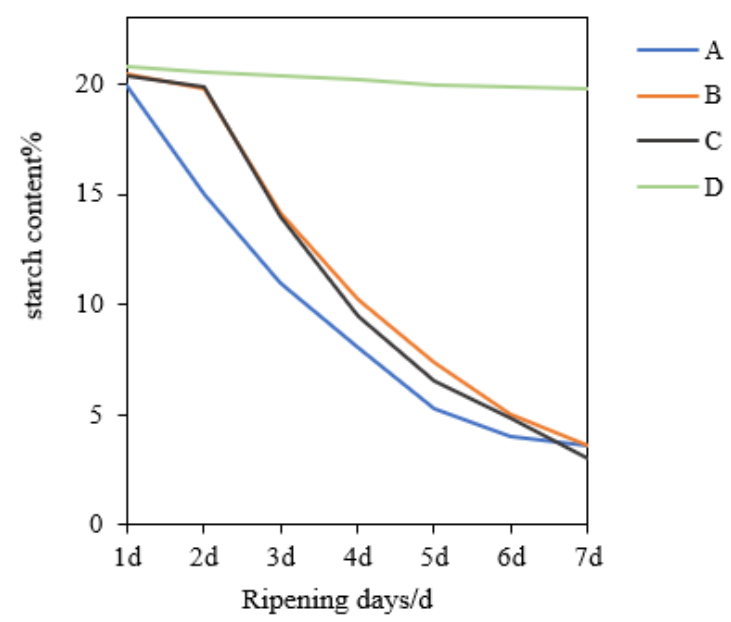

Fig. 11. Changes of starch content during ripening of banana

\subsubsection{Changes of Respiratory Intensity and Ethylene Release Rate}

Figure 12 demonstrates the respiratory intensity in Groups A and $\mathrm{C}$ initially increased and then decreased during ripening, thereby reaching the maxima of 120.6 and $125.7 \mathrm{CO}_{2} / \mathrm{kg} \cdot \mathrm{h}$, respectively, on the sixth day. In Group $\mathrm{B}$, the respiratory intensity had been increasing. Group D had no distinct change in terms of respiratory intensity. The growth rate of respiratory intensity in Group $\mathrm{C}$ was faster than those of Groups A and B. The respiratory intensity of bananas in Group $\mathrm{C}$ had been at its highest since exogenous ethylene was applied on the fourth day and it was stronger than the intensity at a temperature of $16{ }^{\circ} \mathrm{C}$ where bananas ripened. The experimental data showed that high temperatures, in an appropriate range, could speed up bananas' respiratory intensity, thereby accelerating the after-ripening process.

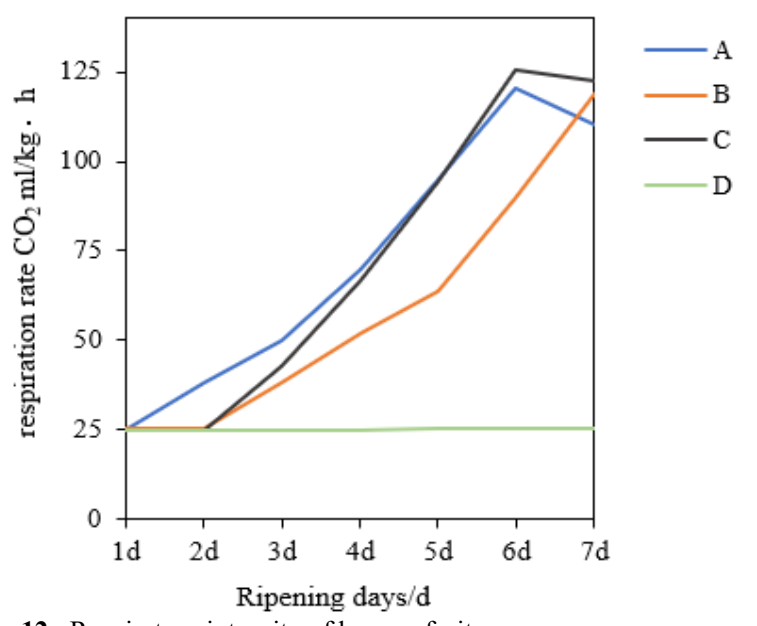

Fig. 12. Respiratory intensity of banana fruit

Figure 13 presents that the ethylene release amount in Groups $\mathrm{A}$ and $\mathrm{C}$ initially increased and then decreased 
during ripening, thereby reaching the maxima of 11.7 and $11.9 \mu \mathrm{L} / \mathrm{kg} \cdot \mathrm{h}$, respectively, on the sixth day. In Group B, the ethylene release amount had been increasing. Group D exhibited no distinct change. The growth rate of ethylene release amount in Group $\mathrm{C}$ was faster than those of Groups $\mathrm{A}$ and B. The experimental data showed that high temperatures, in an appropriate range, could promote bananas' ethylene release, thereby accelerating the ripening process.

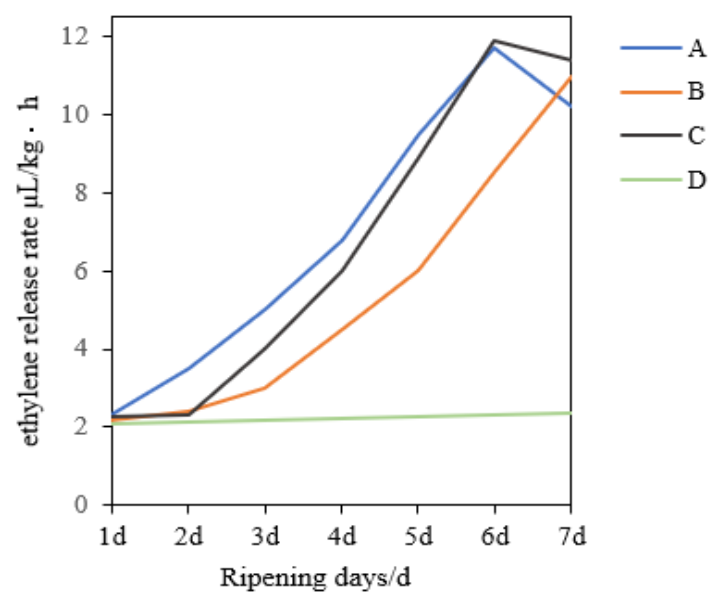

Fig. 13. Ethylene release rate of banana fruit

\subsubsection{Changes of Soluble Solids}

Figure 14 demonstrates that soluble solids in Groups A and $\mathrm{C}$ initially increased and then decreased during ripening. In Group B, soluble solids showed an upward trend. Group D had no distinct change in terms of soluble solids. The amounts of soluble solids in Groups $\mathrm{A}$ and $\mathrm{C}$ reached the maxima of $20.96 \%$ and $22.31 \%$, respectively, on the sixth day. Bananas of Group $\mathrm{C}$ had more soluble solids than that of Group B. The experimental data showed that high temperatures, in an appropriate range, could enhance bananas' ripeness, thereby accelerating the increase of soluble solids.

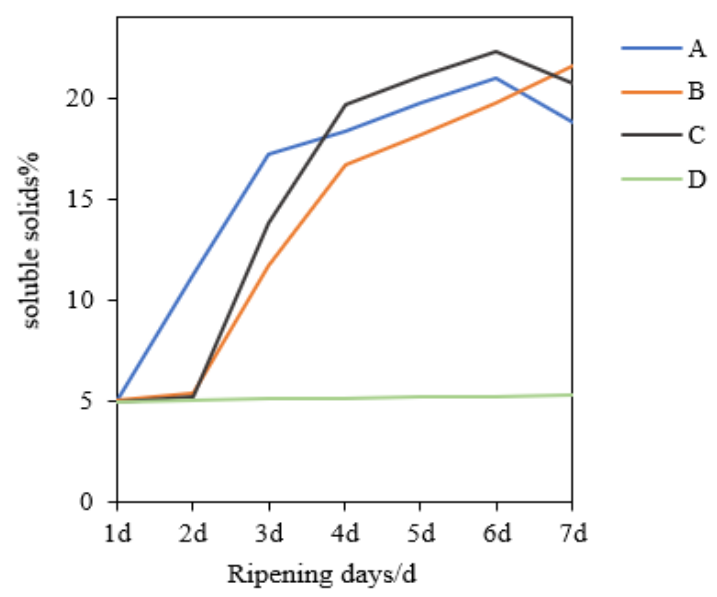

Fig. 14. Changes of soluble solid content during ripening of banana

\subsubsection{Changes of Ripeness}

The ripeness level of bananas through the sixth day of transportation experiments was measured when the vehicle arrived at the destination. Data indicated that experiment results were close to the expected results. The ripeness level reached $70 \%$ when the vehicle with Group $\mathrm{A}$ and $\mathrm{C}$ bananas arrived at the destination but $60 \%$ with in Group B bananas. Ripeness remained the same in Group D at $40 \%$.
The experiment results demonstrate that bananas, after proper ethylene treatment, speed up their own respiration, and increasing the amount of ethylene release can accelerate the ripening. Appropriate temperatures are conducive to bananas' after-ripening. Starch conversion rate is gradually quickened as the temperature rises. The shorter the softening time is, the glossier the peel is, and the higher the soluble solid content in equal times is, thereby indicating that high temperature will accelerate bananas' ripeness. Ethylene treatment for banana fruit improves the respiratory intensity and promotes the decrease of firmness and starch content. To some extent, the after-ripening process is altered after bananas are treated with ethylene. Therefore, exogenous ethylene and temperature have effects on bananas' afterripening, which can be applied to transportation management. Bananas can achieve an ideal ripeness level during transportation by regulating carriage temperature and the time in which exogenous ethylene is applied.

\section{Conclusions}

This study started with a novel transportation method by ripening gas concentration control, designed the bidirectional controlled atmosphere method, and proposed a dynamic control method based on temperature and ethylene concentration regulation to accomplish the dynamic control of ripening gas atmosphere during transportation. The feasibility that ripeness level can be controlled by changing temperatures and exogenous ethylene was verified through the comparative experiments of bananas in actual transportation. Various indexes, including colorimetry, firmness, starch content, respiratory intensity, ethylene release rate, and soluble solids, were considered. The following conclusions could be drawn:

(1) The multi-functional controlled atmosphere method, which is dominated by ethylene concentration regulation, utilizes the central gas treatment layer to divide the carriage into Zones A and B. The ethylene-generating and intakeand-exhaust units separately control ethylene concentration inside the carriage. The ripeness level control of respiration climacteric products can be achieved during transportation, thereby improving the transportation efficiency.

(2) Under the working status, the air circulation method can realize its full circulation to ensure that the gas in the carriage is evenly distributed. Simultaneously, the refrigeration unit is operating to control the carriage temperature by constructing temperature fields in various states of ripening to achieve the expected and desired results. (3) Level pressure is achieved during transportation, which reduces the squeezing and collision of goods, by using a special loading-and-unloading method, thus lowering transportation loss.

This novel transportation method can not only ripen respiration climacteric products during transportation on the basis of different demands but solve the squeezing problems when loading and unloading. In comparison with the regular transportation vehicle, this method can address the problem of fruit damage caused by overripeness as well as avoid extra later-ripening when fruits arrive at the destination and are delivered to special controlled atmosphere storage. This condition saves costs and ensures taste and quality. Further work is required with respect to the determination of ripening parameters of other fruit-vegetable products, except bananas. 


\section{Acknowledgements}

This study was supported by Science and technology program of colleges and universities in Shandong Province (J18KB033 and J14LN66).
This is an Open Access article distributed under the terms of the Creative Commons Attribution License

\section{References}

1. Guo, J., Wei, X., Lu, E., Wang, Y., "Ripening behavior and quality of 1-MCP treated d'Anjou pears during controlled atmosphere storage". Food Control, 117, 2020, pp.1-10.

2. Zhang, P., Zhang, H., Chen, S., Ren, C., Zhu, Z., Li, Z., "Status and Considerations for Development Strategy of the Industry of Logistics and Storage of Fruits and Vegetables in China". Storage and Process, 13(4), 2013, pp.1-5.

3. Miguel, G. R., Alejandra, M., Orianne, G., Sofia, Z., "Biosynthesis of fatty acids-derived volatiles in 'Hass' avocado is modulated by ethylene and storage conditions during ripening". Scientia Horticulturae, 202, 2019, pp.91-98.

4. David, S., Sally, R. B., "Induction of ripening capacity in 'Packham's Triumph' and 'Gebhard Red D'Anjou' Pears by temperature and ethylene conditioning". Postharvest Biology and Technology, 91, 2014, pp.84-89.

5. Zhu, X., Lin, S., Fu, D., Si, Z., Wu, B., Chen, W., Li, X., "Effects of the combination treatment of 1-MCP and ethylene on the ripening of harvested banana fruit". Postharvest Biology and Technology, 107, 2015, pp.23-32.

6. Watharkar, R. B., Pu, Y., Ismail, B. B., Srivastava, B., Srivastav, P. P., Liu, D., "Change in physicochemical characteristics and volatile compounds during different stage of banana (Musa nana Lour vs. Dwarf Cavendish) ripening".Journal of Food Measurement and Characterization, 14(4), 2020, pp.2040-2050.

7. Tan, L., Ijaz, U., Salih, H., Cheng, Z., Ge, Y., Azeem, F., "GenomeWide Identification and Comparative Analysis of MYB Transcription Factor Family in Musa acuminata and Musa balbisiana". Plants-Basel, 9(4), 2020, pp.413.

8. Lu, L., Xin, L., Guang, C., "The risk management of perishable supply chain based on coloured Petri Net modeling”. Information Processing in Agriculture, 5(1), 2018, pp.112.

9. Dhakshinamoorthy, D., Sundaresan, S., Iyadurai, A., Subramanian, K. S., Janavi, G. J., Paliyath, G., Subramanian, J., "Hexanal Vapor Induced Resistance against Major Postharvest Pathogens of Banana (Musa acuminata L.)". Plant Pathology Journal, 36(2), 2020, pp.133-147.

10. Zhu, X., Song, Z., Li, Q., Li, J., Chen, W., Li, X., "Physiological and transcriptomic analysis reveals the roles of 1-MCP in the ripening and fruit aroma quality of banana fruit (Fenjiao)". Food Research International, 130, 2020, pp.108968.

11. Noordia, A., Mustar, Y. S., Kusnanik, N. W., "Foam mat drying of banana juice: varieties of ripe banana analysis and egg albumen foam". Food Science and Technology, 40(2), 2020, pp.465-468.

12. Zhang, J., Miao, H., Xie, B., Wang, J., Jia, C., Zhang, J., Xu, B., Jin, Z., Liu, J., "Genomic and Transcriptional Analysis of Banana Ovate Family Proteins Reveals Their Relationship with Fruit Development and Ripening”. Biochemical Genetics, 58(3), 2020, pp.412-429.

13. Solis, E., Agama, E., “ADP-Glucose Pyrophosphorylase Is Located in the Plastid and Cytosol in the Pulp of Tropical Banana Fruit (Musa acuminata)". Plant Foods for Human Nutrition, 75(1), 2020, pp.76-82.

14. Song, C., Shan, W., Kuang, J., Chen, J., Lu, W., "The basic helixloop-helix transcription factor MabHLH7 positively regulates cell wall-modifying-related genes during banana fruit ripening". Postharvest Biology and Technology, 161, 2020, pp.111068.

15. Brat, P., Bugaud, C., Guillermet, C., Salmon, F., "Review of banana green life throughout the food chain: From auto-catalytic induction to the optimisation of shipping and storage conditions". Scientia Horticulturae, 262, 2020, pp.109054.

16. Wang, B., Zhang, J., Wang, J., Zhang, X., Ma, C., Li, B., "Optimum temperature for banana gas ripening". Journal of Southern Agriculture, 47(12), 2016, pp.2139-2144.
17. He, X., Li, L., Sun, J., "Adenylate quantitative method analyzing energy change in postharvest banana (Musa acuminate L.) fruits stored at different temperatures". Scientia Horticulturae, 219, 2017, pp.118-124.

18. Kargar, M., Woods, F. M., Wall, M. M., Kessler, J. R., Fonsah, E. G., Jeganathan, R. B., Larsen, N., "Influence of Ripening and Cultivar on Banana Peel and Pulp Browning: The Role of Phenylalanine Ammonia-lyase (PAL) and Lipoxygenase (LOX) Enzymes". Hortscience, 54(9), 2019, pp.384.

19. Rayo, L. M., Gomez, A. V., Tadini, C. C., "Extraction of soluble sugars from banana puree to obtain a matrix rich in non-starch polysaccharides". Food Chemistry, 294, 2019, pp.539-546.

20. Shang, Z., Zhang, Y., Wang, M., "Effect of $40 \%$ ethephon on banana quality". Tropical Agricultural Sciences, 34(6), 2014, pp.103-114.

21. Borges, C. V., Minatel, I. O., Amorim, E. P., Correa, C. R., "Ripening and cooking processes influence the carotenoid content in bananas and plantains (Musa spp.)". Food Research International, 24, 2019, pp.129-136.

22. Priyanka, R., Chaudhary, G. K., Bhimanagouda, S. P., "Ethylene degreening modulates health promoting phytochemicals in Rio Red grapefruit". Food Chemistry, 188, 2015, pp.77-83.

23. Sooyeonl, L. J., Gu, L. E., "Comparison of fruit quality and GCMS-based metabolite profiling of kiwifruit 'Jecy green': Natural and exogenous ethylene-induced ripening". Food Chemistry, 234, 2017, pp.81-92.

24. Maarten, L. A. T. M., Peter, B., "A mechanistic model to describe the effects of time, temperature and exogenous ethylene levels on softening of kiwifruit". Postharvest Biology and Technology, 121, 2016, pp.143-150.

25. Clara, I., Geert, V. R., "Omics analysis of the ethylene signal transduction in tomato as a function of storage temperature". Postharvest Biology and Technology, 155, 2019, pp.1-10.

26. Lorenzo, A., Florence, P., "Thap Maeo bananas: Fast ripening and full ethylene perception at low doses". Food Research International, 105, 2018, pp.384-392.

27. Qian, Z. Q., Andrew, R., "East Modelling ethylene regulated changes in 'Hass' avocado quality". Postharvest Biology and Technology, 136, 2018, pp.12-22.

28. Meng, C., Huang, P., Bi, F., "Design of ethylene ripening system for fruits and vegetables and banana ripening experiment". Acta Pomology Sinica, 35(3), 2018, pp.376-384.

29. Robert, S., Leon, A., "Design and construction of a flexible laboratoryscale mixing apparatus for continuous ethylene supplementation of fresh produce". Biolo methods engineering, 157, 2017, pp.86-91.

30. Liang, R., Zhang, J., Tan, R., Li, Y., "Design Process Model and Application of the Existing Product Function Innovation". Journal of Mechanical Engineering, 52(23), 2016, pp.50-61.

31. Duan, X., Pang, X., Zhang, Z., Ji, Z., "Effect of Cold Shock Treatment on Some Postharvest Physiological Activities of Banana under the High Temperature Condition". Journal of Tropical Crops, (2), 2002, pp.31-35.

32. Su, X., Wang, E., Zheng, Y., "Study on dynamic prediction of banana quality index during logistics storage and transportation". Food science, (10), 2008, pp.604-607.

33. Ministry of health of the people's Republic of China, " $G B / T$ 5009.9-2008, determination of starch in food". Beijing: China Standard Press, China, 2008.

34. Lian, S., Hao, L., Wang, Y., "Study on quality change of banana during ripening". Agricultural products processing, 39(12), 2014, pp.54-58.

35. Voss, D. H., "Relating colorimeter measurement of plant color to the Royal Horticultural Society Colour Chart". HortScience, 27(12), 1992, pp.1256-1260. 